\title{
Water effect on the new catalyst of high temperature shift conversion during first reduction
}

\author{
Mohamed A. Fouad M. Gaber ${ }^{1}$
}

Received: 13 October 2018 / Accepted: 16 November 2018 / Published online: 4 December 2018

(c) The Author(s) 2018

\begin{abstract}
The water-gas shift reaction plays a major role in ammonia and hydrogen plant design and operation. Good performance of the shift catalysts, and attainment of a close approach to equilibrium and, hence, minimization of the CO slip from the catalyst system is critical to the efficient and economic operation of the plant and ensures maximum hydrogen production from the hydrocarbon feedstock. Excessive drying out of catalyst during first reduction was studied to identify its influence on the catalyst during normal operation.
\end{abstract}

Keywords Shift conversion catalyst . Catalyst reduction $\cdot$ Ammonia plant $\cdot$ Hydrogen plant $\cdot$ Water effect

\section{Introduction}

The water gas shift reaction is an essential step in modern ammonia plants. Efficient and reliable shift conversion is required to ensure that the highest yield of hydrogen can be obtained from the reformed hydrocarbons. Hence, good performance of the shift catalyst and attainment of equilibrium CO slip from the catalyst system is critical for the efficient and economic operation of the plant to maximize the hydrogen production from the plant. In most ammonia plants, the shift conversion is carried out in two stages. Usually, a high temperature shift (HTS) catalyst is used as the first stage and typically converts over $80 \%$ of the CO. A low temperature shift catalyst (LTS) then converts the majority of the remaining $\mathrm{CO}$ [1]. As well as maximizing the hydrogen production, the water gas shift reaction also maximizes the $\mathrm{CO}_{2}$ production from an ammonia plant. In addition, carbon oxides, both carbon monoxide and carbon dioxide (COx), are a poison to the ammonia synthesis catalyst and, therefore, must be removed. $\mathrm{CO}$ is converted into $\mathrm{CO}_{2}$ for easier removal in the $\mathrm{CO}_{2}$ removal system. $\mathrm{CO}_{2}$ is an essential component for the Urea plant [1].

The high temperature shift (HTS) catalyst is comprised of iron oxide, with a chromium oxide stabilizing agent to

Mohamed A. Fouad M. Gaber

mohamedfouad56@yahoo.com

1 Chemical Engineering Department, Faculty of Engineering, Alexandria University, P. O. Box 21544, Alexandria, Egypt reduce the rate of sintering of the active iron crystallites at high temperatures [2]. More recently, copper has been added to the formulation to increase the activity per unit bed volume and to provide protection against catalyst over-reduction at low steam-gas ratios [3]. Typical operating temperatures for a high temperature shift catalyst are between 310 and $460{ }^{\circ} \mathrm{C}$ and at this temperature, a new catalyst charge should be able to reduce the $\mathrm{CO}$ level at the reactor exit close to the equilibrium level of the process conditions, usually in the range $2-3 \mathrm{~mol} \%$. At these temperatures, iron has sufficient activity to deliver the required performance.

Virtually, all high temperature shift catalysts are in the form of pellets of $\mathrm{Fe}_{2} \mathrm{O}_{3} / \mathrm{Cr}_{2} \mathrm{O}_{3} / \mathrm{CuO}$, with $88 \%, 9 \%$, and $2.6 \%$, respectively. A small level of residual impurities are from the manufacturing process, primarily sulfur (production specification $<0.025 \mathrm{wt} \%$, typically $<0.01 \mathrm{wt} \%$ for 71-5) [4]. The active phase of iron oxide is magnetite, $\mathrm{Fe}_{3} \mathrm{O}_{4}$, and so the catalyst must be reduced to the fully activate the catalyst. The reduction of a high temperature shift charge normally occurs at the same time as the reduction of the reforming catalyst, as both process gas and steam are needed for a controlled reduction to occur. The equilibrium point is controlled by the $\mathrm{H}_{2} \mathrm{O} / \mathrm{H}_{2}$ and the $\mathrm{CO}_{2} / \mathrm{CO}$ ratios. It is important to have steam present as a part of the reduction process as it moderates the reduction effect. Otherwise, the catalyst would over-reduce to metallic iron. It can be shown that if the $\mathrm{H}_{2} \mathrm{O} / \mathrm{H}_{2}$ ratio exceeds 0.18 at $400{ }^{\circ} \mathrm{C}$, then the desired magnetite is the stable phase $[1,4]$. 
Ammonia plant in fertilizer Company has high temperature shift converter with catalyst volume about $60 \mathrm{~m}^{3}$ with two beds, the two-bed catalyst was changed during turnaround by another new catalyst batch of (Johnson Matthey catalyst). During first reduction of primary reformer and high temperature shift conversion, the catalyst bed temperature of high temperature shift converter increased sharply for few minutes. In this short note, we will discuss this phenomenon to identify its influence on the catalyst life time and performance during normal operation.

\section{Case study}

\section{Normal high temperature shift conversion catalyst reduction $[5,6]$}

a. Purge the reactor free of air with inert gas.

b. If possible, heat the catalyst bed with dry gas until the process gas condensation temperature is exceeded. Alternatively, heat the catalyst with process gas and allow the effluent gas to go to the vent. Pressurization to system pressure can be carried out at any time during the reduction. The process gas and steam flow combined should give a space velocity of approximately $200-1000 \mathrm{~h}^{-1}$.

c. Raise the catalyst temperature to $300^{\circ} \mathrm{C}$ at up to $50{ }^{\circ} \mathrm{C}$ per hour. Reduction begins around $150^{\circ} \mathrm{C}$.

d. The CO shift reaction will begin around $300-320{ }^{\circ} \mathrm{C}$ and the observed temperature rise will depend upon the inlet $\mathrm{CO}$ content and steam-gas ratio. The inlet gas must contain less than $15 \% \mathrm{CO}$ (wet basis) because the maximum allowable temperature at this stage is $500{ }^{\circ} \mathrm{C}$. A typical composition of dry gas would be $68 \% \mathrm{H}_{2}, 14.5 \%$ $\mathrm{N}_{2}, 14 \% \mathrm{CO}, 1.5 \% \mathrm{CO}_{2}$, and $2 \% \mathrm{CH}_{4}$ [1].

e. Raise the inlet temperature to at least $370{ }^{\circ} \mathrm{C}$ and hold for several hours. This allows any residual sulfur from the manufacturing process to be converted into $\mathrm{H}_{2} \mathrm{~S}$ and driven off. This temperature should be held until the sulfur level has removed or reduced to the enough level $0.5 \mathrm{ppm}$ according to the next reaction in the desulfurization unit:

$\mathrm{RS}+\mathrm{H}_{2} \rightarrow \mathrm{H}_{2} \mathrm{~S}+\mathrm{RH}$

The hydrogen sulfide can be converted into zinc sulfide by passing through zinc oxide catalyst.

$\mathrm{H}_{2} \mathrm{~S}+\mathrm{ZnO} \rightarrow \mathrm{ZnS}+\mathrm{H}_{2} \mathrm{O}$

Sulfur is considered poison for the low temperature shift conversion catalyst. The desulfurization period should be only $4 \mathrm{~h}$ from the first introduction of gas.

f. Adjust the bed inlet temperature and process gas rate to operating values. The catalyst is now fully activated and the process gas can now be passed forward to the next step.

\section{Excessive increasing of catalyst temperature during first reduction}

Hydrogen plant in fertilizer CO. has high temperature shift converter with two beds each bed has a catalyst volume $30 \mathrm{~m}^{3}$ and has thermo elements on the inlet and outlet and catalyst beds as shown in the Fig. 1, the new catalyst batch charged in august 2014 while the plant was started up on 5 October (due to shortage in Natural gas in EGYPT.

High temperature shift catalyst reduction was started with heating up for front end by $\mathrm{N}_{2}$ circulation was started on 5th October 2014 and continued to 7 th October 2014 (for about $37 \mathrm{~h}$ ), $\mathrm{N}_{2}$ circulation was stopped on 7 th October 2014 at 1:30 a.m., steaming for front end was started by adding two tons of steam to the $\mathrm{N}_{2}$ circulation and the steam condensed in 306E003 this two tons of steam continued to about $10 \mathrm{~min}$, then steam flow increased to 25 tons at the same time of $\mathrm{N}_{2}$ Circulation stoppage steam flow was $25 \mathrm{ton} / \mathrm{h}$. for about $20 \mathrm{~min}$ and then increased to $35 \mathrm{ton} / \mathrm{h}$. After increasing the steam flow to 35 ton/h, 25 min later, it was observed that the catalyst beds temperature increased sharply as shown in the Table 1.

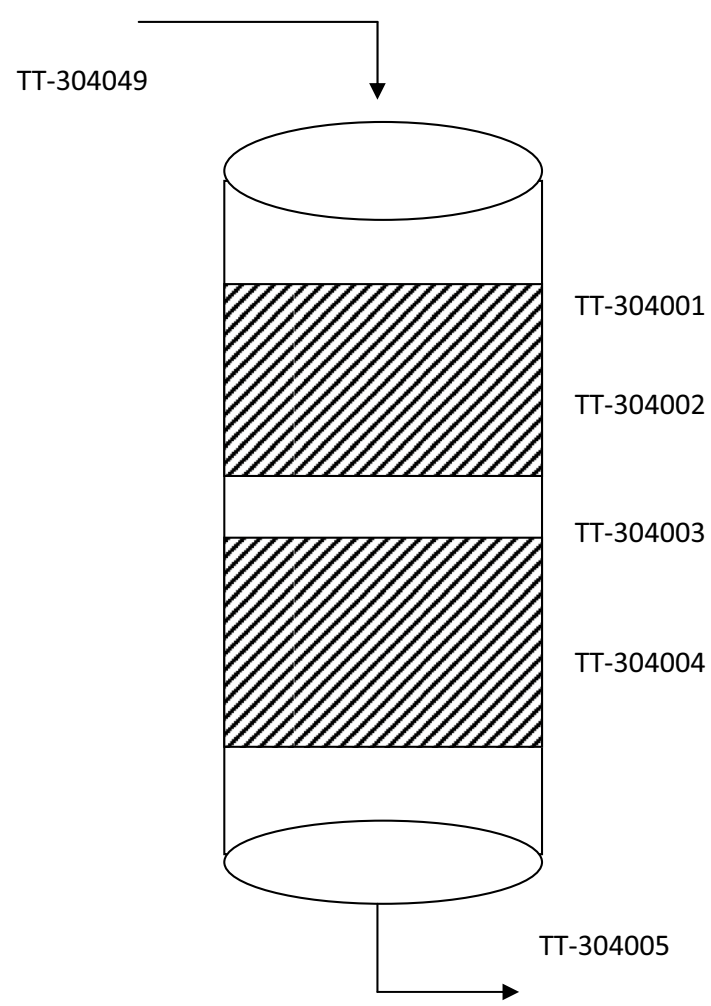

Fig. 1 High temperature shift conversion catalyst 
Table 1 Temperature profiles of high temperature shift catalyst during reduction

\begin{tabular}{lll}
\hline Thermo element no. & Starting temperature & $\begin{array}{l}\text { Highest } \\
\text { tempera- } \\
\text { ture }\end{array}$ \\
\hline TT-304002 & 266 & 308 \\
TT-304003 & 260 & 330 \\
TT-304004 & 277 & 452 \\
TT-304005 & 233 & 347 \\
\hline
\end{tabular}

As shown in the above table, the maximum temperature jumped was (TT-304004) outlet temperature of second bed.

When the plant operated at load about $90 \%$, the performance of high temperature shift converter in terms of delta $\mathrm{P}$ and CO slip were in acceptable level, which means the catalyst was not affected by shooting up of catalyst bed temperature during steaming or first catalyst reduction. The temperature profile of catalyst was close to the design temperature.

\section{Phenomena discussion}

Under normal conditions, the surface of the fresh high temperature shift conversion catalyst is covered with hydroxyl groups. After the catalyst exposed several hours to $\mathrm{N}_{2}$ circulation during first reduction at temperatures seen in during heating up the high temperature shift conversion catalyst, the hydroxyl groups are stripped away leaving very active $\mathrm{Fe}-\mathrm{O}-\mathrm{Fe}$ groups on the surface of the catalyst [6]. This surface readily rehydrates when steam is introduced prior to introduction of process gas, releasing heat [5]. Only a small portion of steam reacts with the surface and the most of the steam acted as a heat carrier. This means that the bottom layer of the catalyst was heated up not only by rehydration of the catalyst surface, but also by the heat carried down from the top layer of catalyst. This phenomenon only affects the fresh catalyst during first reduction. During first reduction of high temerpature shift catalyst to magnetite form, which has different surface properties to the hematite in fresh catalyst $[6,7]$.

\section{Recommendations}

A care should be taken that if fresh catalyst is exposed to warm dry nitrogen for many hours, the surface of the catalyst will be dehydrated and subsequent rehydration can cause a spectacular exothermic. The exothermic start-up can be avoided by making sure the catalyst is not excessively dried.

If it is necessary for circulation with nitrogen for a long time, the following should be considered:
1. Add a small amount of steam to nitrogen to prevent the drying.

2. Temporarily discontinue the nitrogen circulation.

3. Lower the HTs inlet temperature.

4. If a catalyst has been dehydrated, the size of the subsequent exotherm can be minimized by a high flow to remove the heat generated. Alternatively, steam can be introduced intermittently in pulses with time allowed between pulses for the exotherm to subside.

\section{Conclusion}

Shift catalyst beds temerpature increased sharply during steaming for front end after heating up for front by nitrogen for about $37 \mathrm{~h}$. This exotherm is due to rehydration of the catalyst by steam. This exotherm do not normally cause any catalyst damage. However, some recommendations suggested avoiding excessive drying out of high temperature shift conversion catalyst.

Open Access This article is distributed under the terms of the Creative Commons Attribution 4.0 International License (http://creativeco mmons.org/licenses/by/4.0/), which permits unrestricted use, distribution, and reproduction in any medium, provided you give appropriate credit to the original author(s) and the source, provide a link to the Creative Commons license, and indicate if changes were made.

\section{References}

1. Dybkjær I (1995) Tubular reforming and autothermal reforming of natural gas - an overview of available processes. Fuel Process Technol 42(2-3):85-107

2. Kent JA (2003) Synthetic nitrogen products, in Riegel's handbook of industrial chemistry. Springer, Berlin, pp 1157-1234

3. Ghenciu AF (2002) Review of fuel processing catalysts for hydrogen production in PEM fuel cell ystems. Curr Opin Solid State Mater Sci 6(5):389-399

4. York AP et al (2007) Methane oxyforming for synthesis gas production. Catal Rev 49(4):511-560

5. Liu H (2013) Ammonia synthesis catalysts: innovation and practice. World Scientific, Singapore

6. Sheldon RA (1983) Chemicals from synthesis gas: catalytic reactions of CO and, vol 2. Springer Science \& Business Media, Berlin

7. Barelli L et al (2008) Hydrogen production through sorptionenhanced steam methane reforming and membrane technology: a review. Energy 33(4):554-570

Publisher's Note Springer Nature remains neutral with regard to jurisdictional claims in published maps and institutional affiliations. 